\title{
Study of the Effect of the Geometrical Correction of the Satellite Image on the Global Positioning System Tracking by Using Geographical Information System
}

\author{
Sabah Hussein Ali \\ Remote Sensing Center, University of Mosul, Iraq
}

Abstract. The use of Global Positioning System (GPS) for geometrical correction (rectification) of the satellite imagery aims to establish the relation between the image coordinate system and the GPS readout coordinate system. By using this technique, the errors existing within satellite image can be calibrated and reduced as well.

This paper introduces application of Geographical Information System (GIS) and image processing software in addition to GPS for measuring the coordinates of waypoints to be as ground control points (GCPs) for the geometrical correction process of the QuickBird satellite image for the adopted study area (Mosul City). For comparison purpose, the geodetic rectification process was also done for the adopted QuickBird satellite image with respect to the IKONOS imagery. Due to the low standards in the geometric design characteristics of the road which badly affected the GPS measurements, the output results show that the geodetic rectification of the QuickBird imagery with respect to IKONOS satellite image gives more accuracy of results than GCP acquired by GPS. The overall procedure applied in the present study shows the ability to give an improvement in the positional accuracy of an already georeferenced coordinate system of the QuickBird image which in turn gives a higher accuracy of the GPS tracking path for the purpose of mapping, urban planning, cartography, survey and other GIS applications .

Keyword: Geometrical correction, GPS, Tracking path, GIS, QuickBird, GCP. 


\section{Introduction}

During the satellite imaging process a number of systematic (such as; scan skew, scanner distortion, and variation in scanner mirror velocity) and nonsystematic (such as; variation in the spacecraft attitude, velocity, and altitude) geometrical distortions are introduced into the satellite image data ${ }^{[1]}$. Therefore, it is necessary to correct these distortions before really using the satellite image as a precise measurement data source (especially in the large scale operations). The traditional method for correcting these distortions is establishing mathematical relationships between some highlight and recognizable geographical feature pixels on the image (called ground control point: GCPs) and the corresponding coordinates of these points on the reference map ${ }^{[2]}$. The GCPs will represent a point on the surface of the earth where both image coordinates (measured in rows and columns) and map coordinates (e.g., meters in northing and easting in a Universal Transverse Mercator (UTM) map projection). This is often referred to as an image to map rectification. By using this process each pixel of the image can be referenced not only by its row and column in a matrix after rectification is completed, but it is also referenced in degree, feet, or meters in a standard map projection $^{[3,4]}$.

For Iraq, due to the security circumstances, there is no enough and useful update of the topographic maps since more than ten years ago. Where new constructions and roads were established, these constructions will appear in the satellite image but not yet in the map. Therefore, to solve the problem of the image to map rectification, the present study proposes the use of GPS for acquiring the coordinate of GCPs instead of map. The author expected these data will give more improvement for the geometrical correction than the image to map method.

\section{Theoretical Consideration}

For our proposed procedure, to improve the precision of the image correction, GCPs (identified on a topographical map or in the field by GPS) must be available. These GCPs can be identified in the original imagery, reference map, or by GPS dataset. These GCPs are used to establish a mathematical model to correct the geomantic distortion of image. The GCPs are considered as the coordinates in $(x, y)$ plane, while 
the corresponding coordinates of image pixel are located in $\left(x^{\prime}, y^{\prime}\right)$ plane. The relation between these two coordinate system can be defined by mapping polynomial as the following equation ${ }^{[3]}$.

$$
\begin{aligned}
& x^{\prime}=a_{0}+a_{1} x+a_{2} y \\
& y^{\prime}=b_{0}+b_{1} x+b_{2} y
\end{aligned}
$$

Where:

$x, y$ are the coordinate of the GCPs collected by GPS.

$x^{\prime}, y^{\prime}$ are the corresponding coordinate in the original image.

The coefficients $a_{0}, b_{0}, a_{1}, b_{1}, a_{2}, b_{2}$ can be determined by using the criteria of the least mean square error. After the coefficients are obtained, the coordinates of each image pixel will be transformed ${ }^{[5]}$. The polynomial transformation will be done by using the image processing software (ERDAS Imagine).

\section{Datasets and Software}

\subsection{Datasets}

3.1.1 QuickBird image satellite: The QuickBird satellite has panchromatic and multispectral sensors with resolution of $61-72 \mathrm{~cm}$ and 2.44-2.88m respectively, depending upon the off-nadir viewing angle (0$30^{\circ}$ ). The sensor therefore has a coverage of $16.5-19 \mathrm{~km}$ in the acrosstrack direction ${ }^{[6]}$. The adopted QuickBird image for the present study is a Pan-sharpened image with spatial resolution of $61 \mathrm{~cm}$. The image was acquired at 2007.

3.1.2 IKONOS image satellite: It is a sharpened image satellite, acquired at 2003 with a spatial resolution of $(1 \mathrm{~m})$. It is used for the purpose of GPS dataset comparison with the QuickBird image satellite.

3.1.3 GPS dataset: The measurements of GPS tracklog and the collection of Ground Control Points GCPs were done in situ by using Garmin GPSMAP76SCx unit. The coordinates of the GCPs and the Tracklog were referred to the World Geodetic System 84 (WGS84) ellipsoid using the Universal Transverse Mercator (UTM) projection in the zone of $38 \mathrm{~N}$. 


\subsection{Software Used}

Basically, three softwares were used for this study:

3.2.1 ERDAS Imagine: This was used for the purpose of geometrical correction of the QuickBird satellite image with the collected GCPs.

3.2.2 Global MAPPER10 (GM10.0): This was used for displaying and subsequent processing of the applied layers, GCPs and Tracklog.

3.2.3 ArcGIS9.3: This was also used to complement the display and processing of the data.

\section{Methodology and Processing}

Generally, the QuickBird data is distributed in three different product levels ${ }^{[7]}$ : Basic imagery (designed for advanced imageprocessing applications), Standard imagery (designed for remote sensing applications) and Orthorectified imagery (designed for GIS applications). Each product is supplied with Rational Polynomial Coefficient (RPC) to allow the user to execute the geometrical correction for the imagery without GCPs.

For the present study, due to the unavailability of the (RPC) required to the geometrical correction process of the adopted QuickBird image satellite, GCPs have been measured locally by the author to complete the geometrical correction process and to improve the positional accuracy of the already georeferencing QuickBird image. A total of (5) GCPs (with an average positional accuracy of $\pm 3 \mathrm{~m}$ ) were measured at fixed locations in situ within the study site by using GARMIN GPSmap76CSx unit as shown in Fig. 1.

The five collected GCPs were applied for the rectification procedures to get the optimum number of rectification. Figure 1 illustrates that the GPS tracklog was located inside Mosul city. The start point coordinates of the tracklog is $(\mathrm{E}=334002, \mathrm{~N}=4028476, \mathrm{H}=248 \mathrm{~m})$, while the end point coordinates is $(\mathrm{E}=332125, \mathrm{~N}=4026514, \mathrm{H}=221 \mathrm{~m})$. 


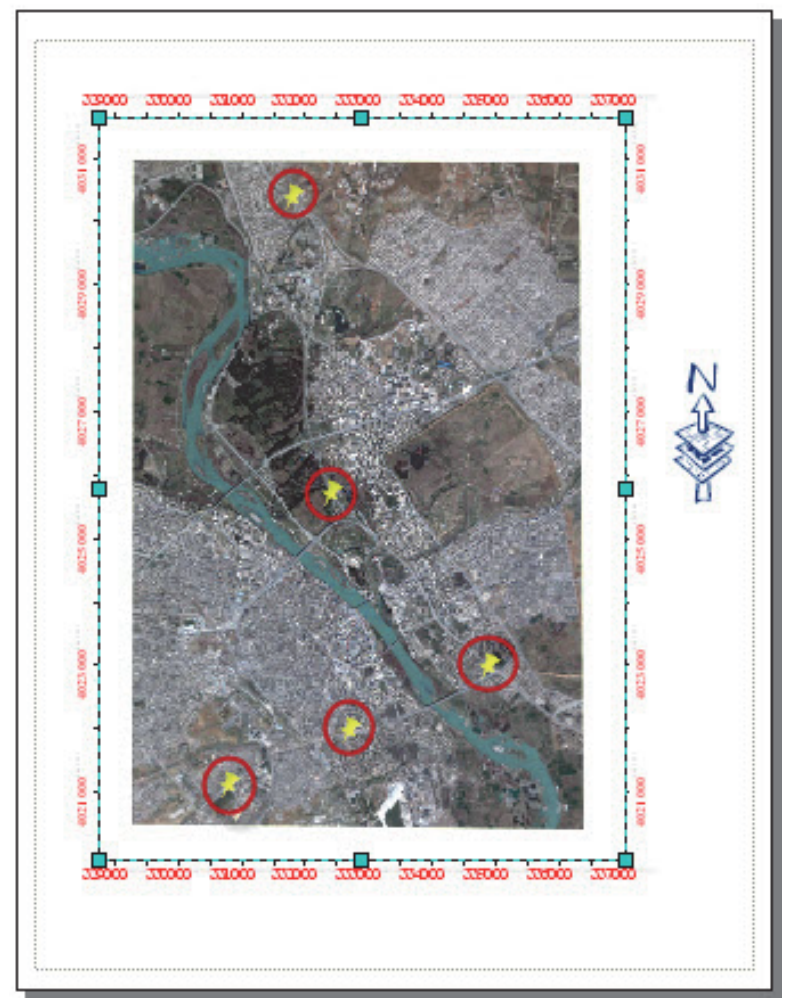

Fig. 1. The GCPs distribution on the QuickBird satellite image of the study site.

ERDAS IMAGINE9.1 software was used for the geometrical correction of the QuickBird satellite image of the study site according to polynomial approach by using the GCPs as shown in Fig. 2. The process in this approach includes calibrating each pixel in the images according to the selected GCPs in order to improve the positional accuracy and the spatial information with low values of Root Mean Square Error $(\mathrm{RMSE})^{[8]}$.

For comparison purpose, the geodetic rectification process was done for the adopted QuickBird satellite image with respect to the IKONOS imagery for the same study site by using the georeferencing toolbar function (first order polynomial approach) in ArcGIS9.3. Figure 3 shows the selected control points applied for the rectification process. 


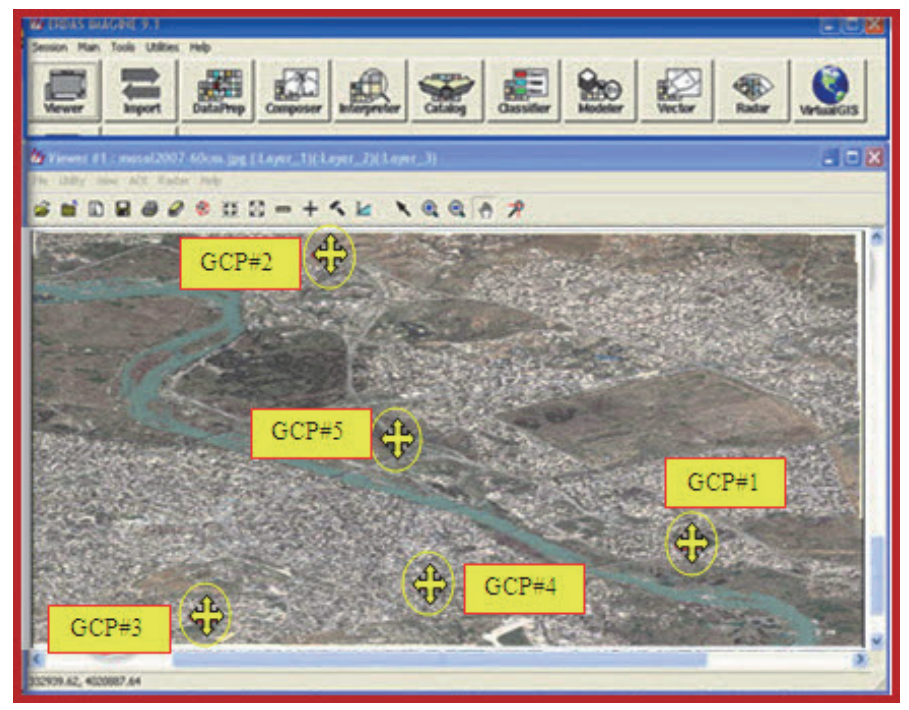

Fig. 2. Geometrical correction process by ERDAS IMAGINE9.1.

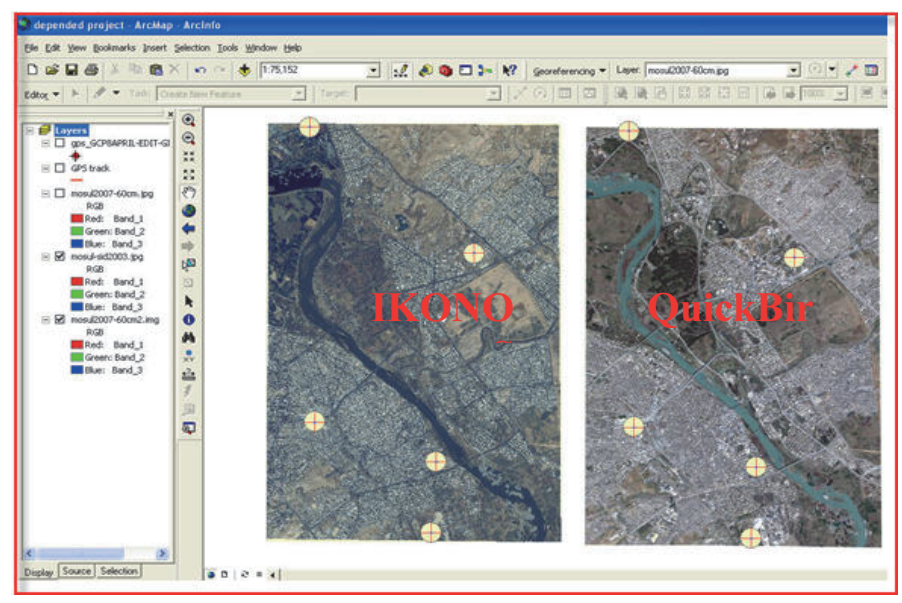

Fig. 3. QuickBird and IKONOS geodetic rectification process by using ArcGIS9.3.

\section{Results and Discussion}

The QuickBird has provided digital imagery with high spatial resolution that is usually needed for the large scale mapping. It is well known that spatial resolution is sufficient for the purpose of mapping, urban planning, surveying and GIS applications ${ }^{[9]}$. Such applications obtained from the QuickBird imagery are often better than other satellite 
images (such as: Landsat -7 ETM+) and aerial photos, but an accurate geometrical geodetic calibration is needed to ensure an accurate output results. The GCPs measured by GPS were used by the geometrical correction process in the present study to establish a geodetic relationship between the image coordinate system (Reference $\mathrm{X}, \mathrm{Y}$ ) and the geographic coordinate system of the measured GCPs ( Input X, Y). Table 1 summarizes the resulting geometric correction dataset.

As shown from the table, the maximum error on the entire image was $(-1 \mathrm{~m})$ on the Easting direction and $(-0.425 \mathrm{~m})$ on the Northing direction. The maximum RMSE is $(1.008 \mathrm{~m})$. Figure 4 shows the RMSE of the locally measured GCPs.

From Table 1 and Fig. 4, it was apparent that the number of (5) GCPs should be enough for image rectification to give an acceptable value of total RMSE of (0.4834).

Table 1. Summary of the QuickBird image geometric correction dataset by ERDAS IMAGINE9.1.

\begin{tabular}{|c|c|c|c|c|c|c|c|}
\hline $\begin{array}{c}\text { Point } \\
\text { ID }\end{array}$ & X Input & Y Input & X Ref. & Y Ref. & $\begin{array}{c}\text { X } \\
\text { Residual }\end{array}$ & $\begin{array}{c}\text { Y } \\
\text { Residual }\end{array}$ & $\begin{array}{c}\text { RMS } \\
\text { Error }\end{array}$ \\
\hline GCP\#1 & 334939.000 & 4022954.000 & 334939.533 & 4022953.354 & 0.133 & 0.160 & 0.208 \\
\hline GCP\#2 & 331848.345 & 4030360.000 & 331847.035 & 4030360.908 & 0.204 & 0.244 & 0.318 \\
\hline GCP\#3 & 330814.000 & 4021080.000 & 330814.563 & 4021080.206 & 0.129 & 0.154 & 0.201 \\
\hline GCP\#4 & 332724.000 & 4021936.000 & 332724.078 & 4021936.117 & 0.534 & -0.425 & 0.682 \\
\hline GCP\#5 & 332448.000 & 4025677.726 & 332446.573 & 4025677.667 & -1.000 & -0.134 & 1.008 \\
\hline
\end{tabular}

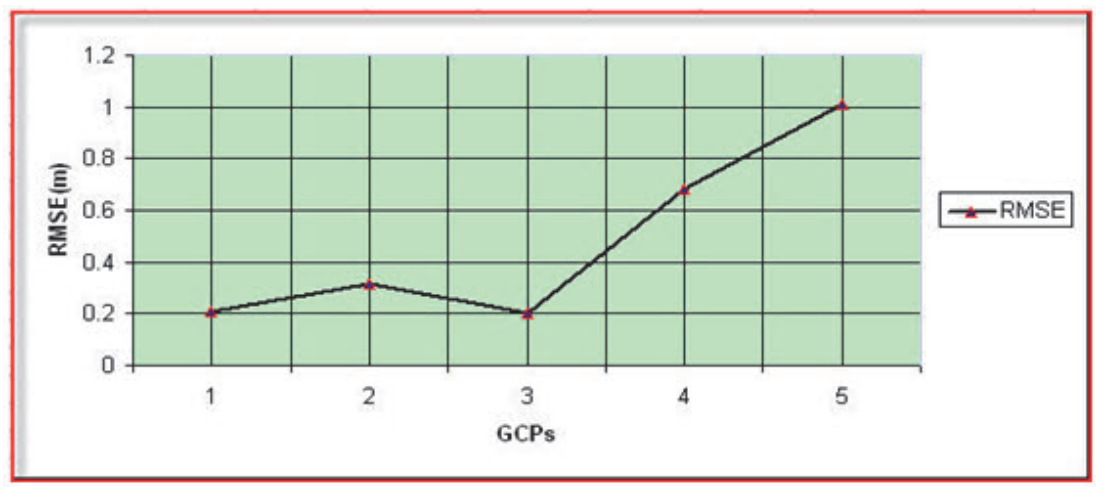

Fig. 4. Plot of GCPs with RMSE. 
On the other side, the output results from the geodetic rectification process as given by ArcGIS9.3 between IKONOS satellite image (X, Y Source) and QuickBird satellite image (X, Y Map) was shown in Table 2. The total resulted RMSE of the rectification process is $(0.78183)$.

Table 2. Summary of the QuickBird image rectification dataset with respect to IKONOS satellite image by ArcGIS9.3.

\begin{tabular}{|c|c|c|c|c|c|}
\hline $\begin{array}{c}\text { ID } \\
\text { Points }\end{array}$ & $\begin{array}{c}\text { X source } \\
\text { (IKONOS) }\end{array}$ & $\begin{array}{c}\text { Y source } \\
\text { (IKONOS) }\end{array}$ & $\begin{array}{c}\text { X Map } \\
\text { (QuickBird) }\end{array}$ & $\begin{array}{c}\text { Y Map } \\
\text { (QuickBird) }\end{array}$ & Residual \\
\hline 1 & 334304.804562 & 4027681.068709 & 334287.765029 & 4027687.524986 & 1.02560 \\
\hline 2 & 333388.251622 & 4022409.070457 & 333376.069103 & 4022411.349221 & 1.37867 \\
\hline 3 & 330345.694849 & 4030849.421447 & 330331.074418 & 4030855.206264 & 0.77331 \\
\hline 4 & 330465.525064 & 4023402.808133 & 330452.668048 & 4023406.257418 & 1.12665 \\
\hline 5 & 333277.815329 & 4020620.045992 & 333265.403583 & 4020622.278672 & 0.00026 \\
\hline
\end{tabular}

To test the effect of the two resulting datasest shown in Tables 1 and 2 on the positional accuracy of the final QuickBird imagery, a real time GPS tracklog in the left side of the Mosul City was recorded. The total length of the tracklog is $(4.73 \mathrm{~km})$. Figure 5 shows the location of the recorded tracklog.

By zooming the tracklog, it is seen that there is a clear spatial displacement of the GPS tracklog from the original location of the street. The spatial displacement varies from minimum value $(5.340 \mathrm{~m})$ to maximum value $(14.564 \mathrm{~m})$ as shown in Fig. 6(a\&b) respectively.

Irregular road pavement surface is the main reason responsible for the shifting of the GPS tracklog. Other reasons found affecting the tracklog are the military checkpoints existing along the track path of the studied road. The above factors enforce the driver to increase or decrease his car acceleration which affect the GPS readout along the testing road. Surely all these reasons have affected the positional accuracy of the GPS and made the shift to appear in Fig. $6(\mathrm{a} \& \mathrm{~b})$. By using the two procedures for the geodetic correction and rectification of the QuickBird satellite image mentioned above, the corrected QuickBird image by the GCP acquired by GPS is shown in Fig. 7, while the corrected QuickBird image by using IKONOS satellite image is shown in Fig. 8. 


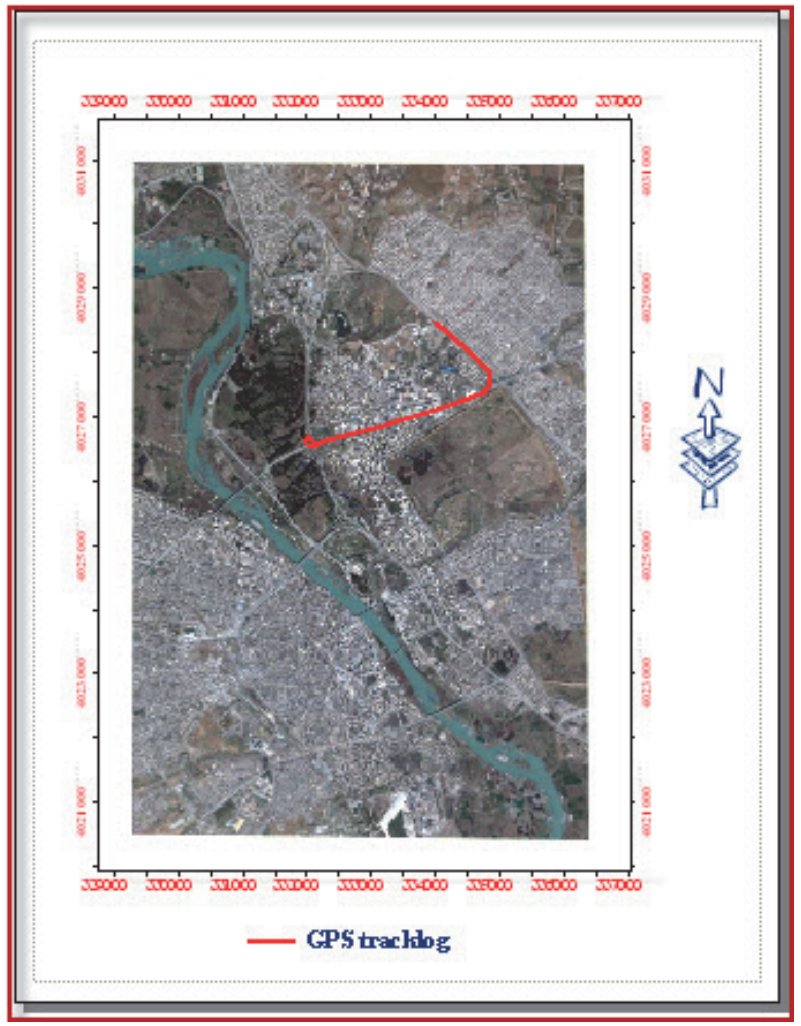

Fig. 5. The location of the recorded GPS tracklog inside Mosul city.

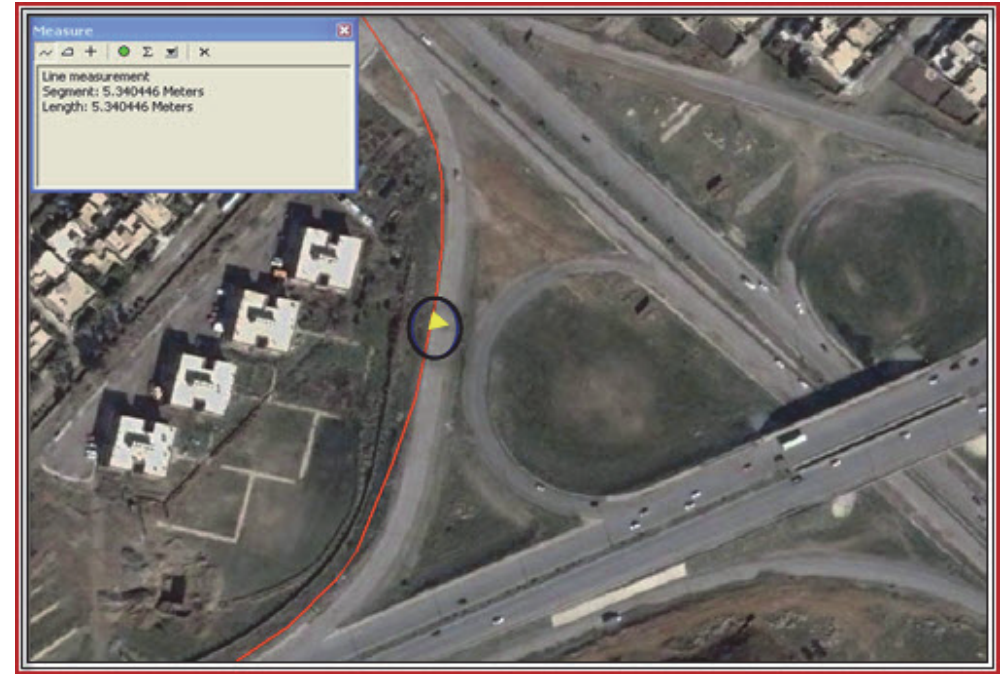

Fig. 6(a). Minimum spatial displacement $=5.340 \mathrm{~m}$. 


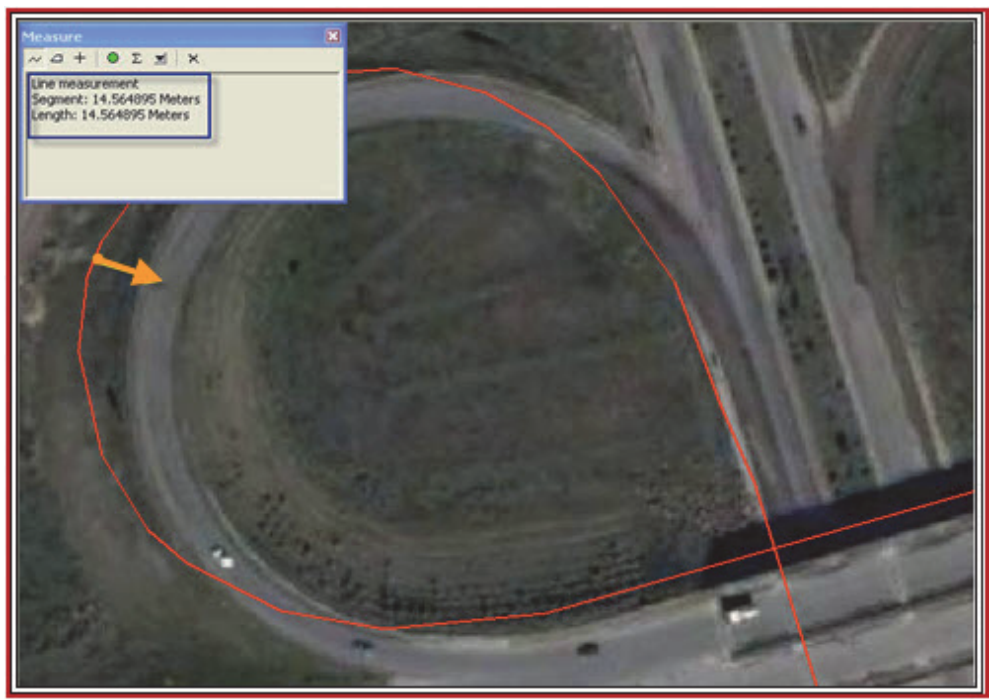

Fig. 6(b). Maximum spatial displacement $=14.564 \mathrm{~m}$.

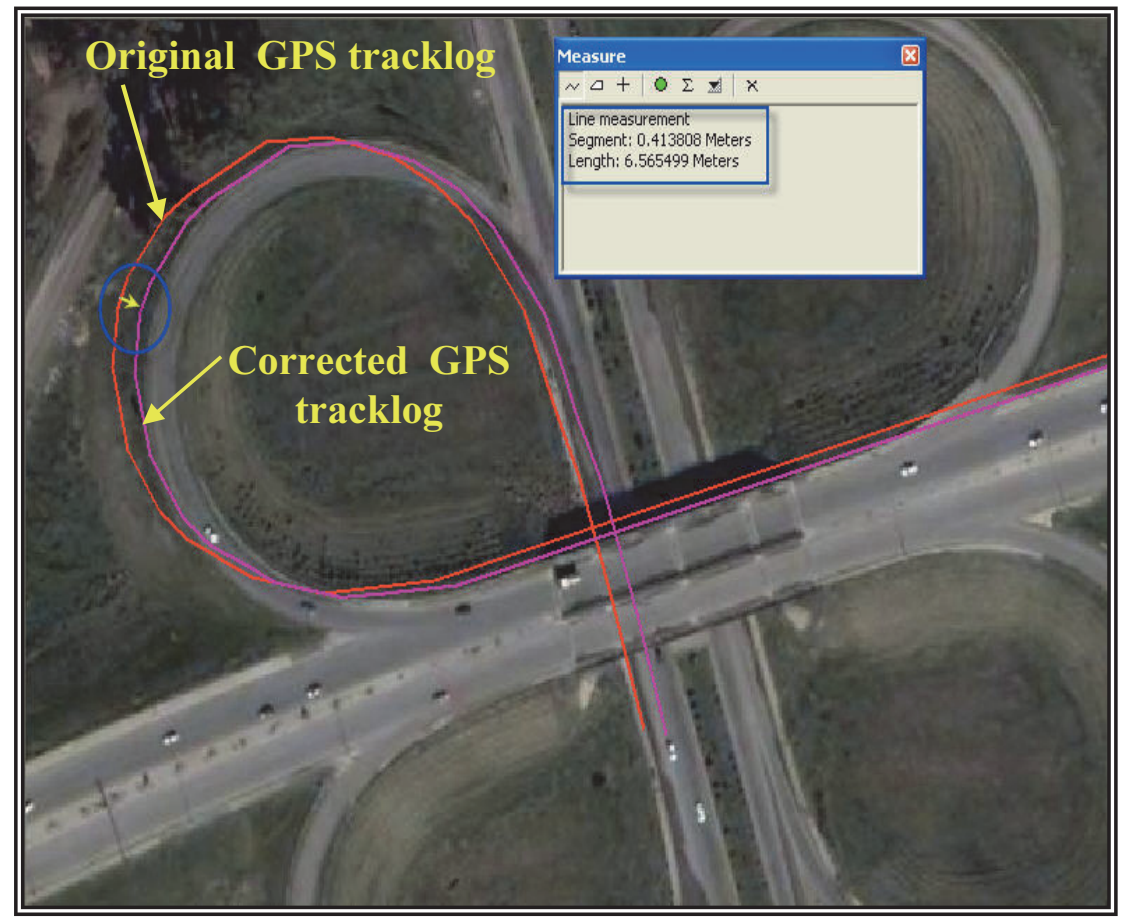

Fig. 7. Geometrical correction image by using GPS. 


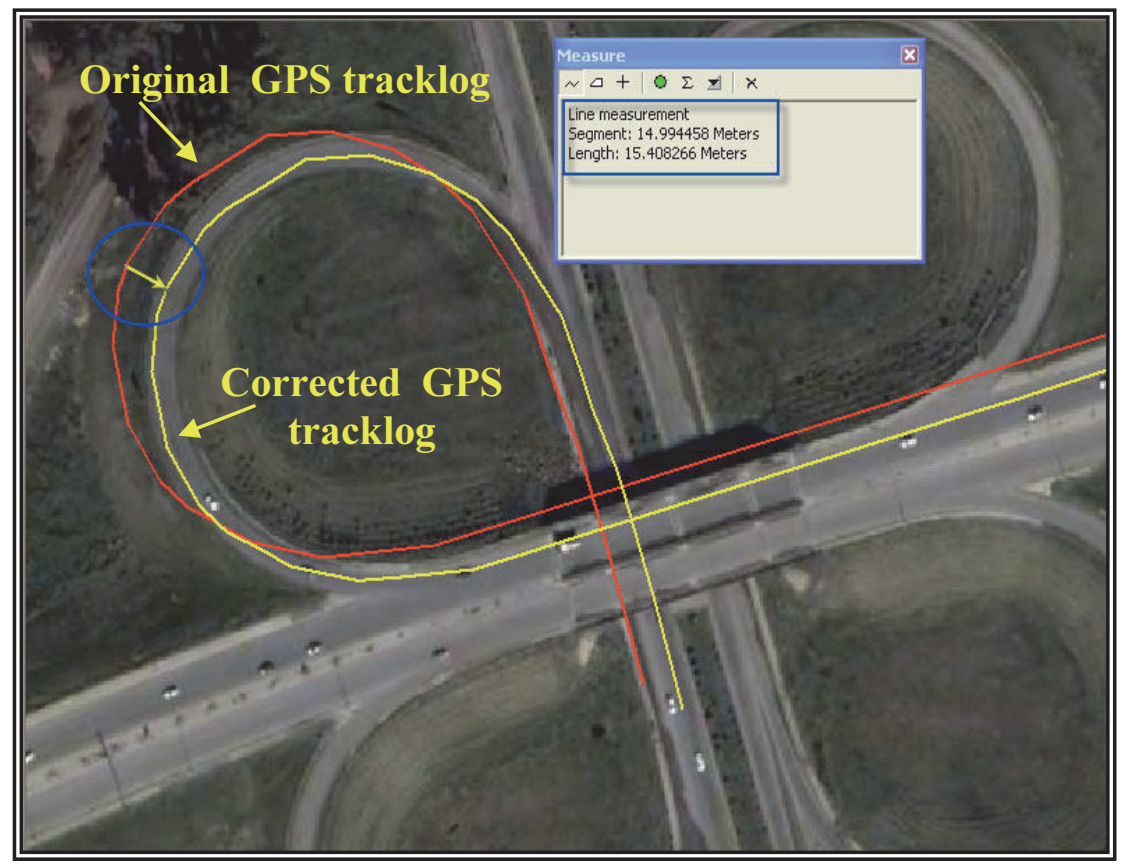

Fig. 8. Geodetic correction image by using IKONOS image.

By comparison between Fig. 6 and 7, it can be seen that the correction by IKONOS satellite image gives an improvement in the positional and spatial accuracy of the QuickBird image so that the GPS tracklog coincide with actual road. This improvement was due to the relative convergence in the spatial properties of the pixels between IKONOS image (spatial resolution=1m) and QuickBird image (spatial resolution $=60 \mathrm{~cm}$ ), while the recorded positional accuracy of the GCPs is about $( \pm 3)$ according to the technical specifications of the available GPS. This accuracy can be improved by using Differential GPS technology which gives a positional accuracy in centimeter units ${ }^{[10]}$, but this technology is very limited in Iraq at the present time.

By using ArcGIS9.3 desktop software, the resulted layout of the final corrected QuickBird satellite image was shown in Fig. 9. 


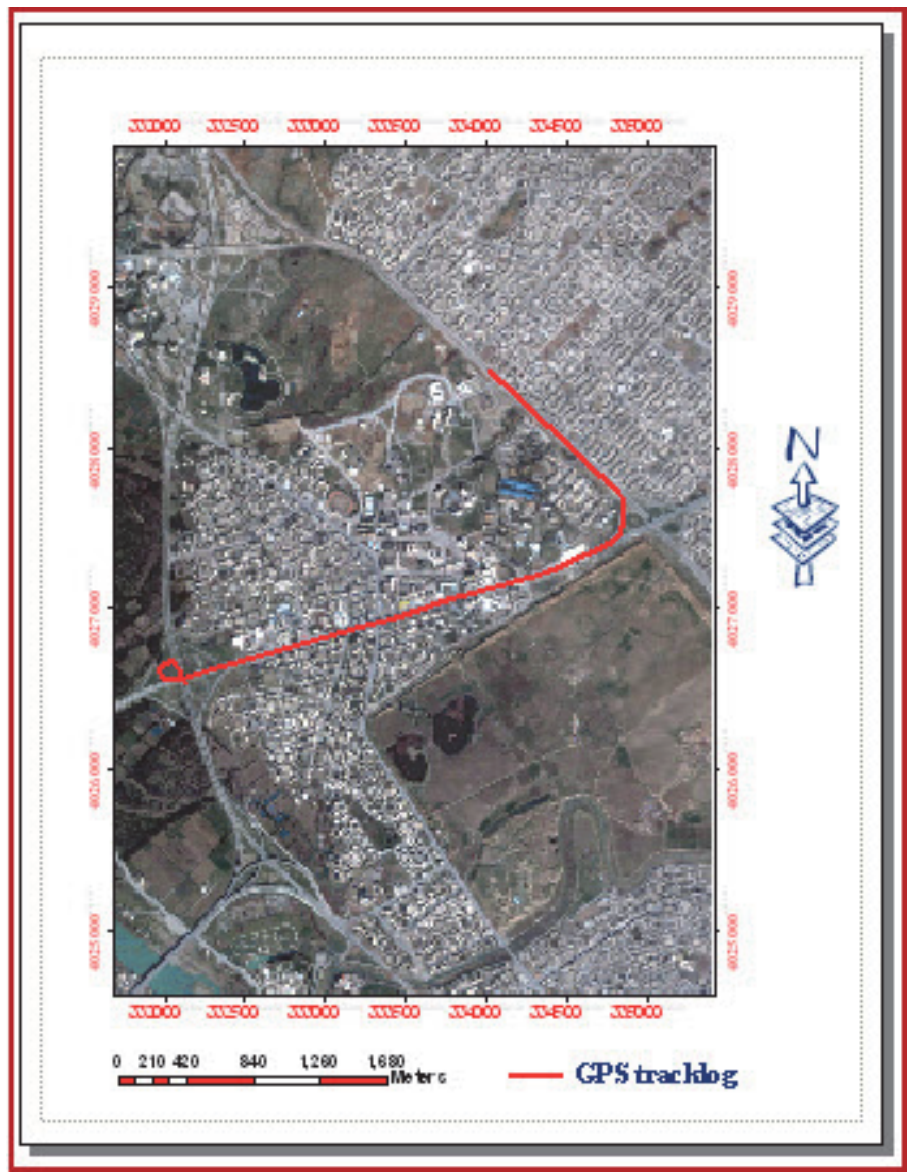

Fig. 9. The layout of the final corrected QuickBird satellite image.

\section{Conclusion}

Geometric correction is one of the preprocessing of remotely sensed satellite image. By realizing this feature, it is possible to correct image rectification and improve the image quality and readability.

In this paper, two methods were applied to perform the geometrical correction of the QuickBird satellite images: the first method relied on the GCPs that have been collected by using GPS technology within the study area, while the second method depends on the rectified IKONOS satellite image. By comparing the output results of the two methods, it was concluded that the geometrical correction and rectification of the 
satellite image in the first method depends mainly on the type and positional accuracy of the used GPS in addition to the integrity characteristics of the road at which the GPS tracklog and GCPs were recorded. Therefore, the accurate positioning of GCPs is essential to an accurate correction.

It is also concluded that the IKONOS satellite image is very important for the geodetic rectification of the available QuickBird imagery and gives more accurate positional accuracy than the adopted GPS used in this study.

\section{References}

[1] Sabins, F., Remote Sensing Principles and Interpretation, W. H. Freeman and Company (1978).

[2] Jalal, A. and Ali., R., "Geometric Correction in Ikonos Images- Case Study, Iran", FIG Working Week and GSD1-8, Cairo, Egypt April 16-21(2005).

[3] Jensen, J., Introductory Digital Image Processing / A Remote Sensing Perspective, Prentice - Hall (1986).

[4] Fazal, S., GIS Basic, New Age International (P) Ltd (2008).

[5] Al- Alaaf, A., "An Interactive Software for Image Registration Using New Algorithms", Msc. Thesis, Univ. of Mosul, Iraq (2002) (In Arabic).

[6] QuickBird High-resolution Satellite Imagery, available at: http://www.landinfo.com/qb.htm, accessed at: 5/April/2011.

[7] Darbha, R., "Geometric Characterization of Ikonos and QuickBird High Resolution Imagery", M. Sci. Thesis, South for Dakota University, USA (2004).

[8] Goshtasby, A., Registration of Image with Geometric Distortions, IEEE Transaction on Geoscience and Remote Sensing, GE26(1):60-64 (1988).

[9] Johnson, J.K., Remote Sensing in Archaeology, The University of Alabama Press (2006).

[10] Reddy, A., Remote Sensing and Geographical Information Systems, 3rd Edition, BSP Publications (2008). 


\title{
دراسة تأثير التصحيح الهندي للبيانات الفضائية على المسار الآني للنظام العالمي لتحديد المواقع باستخدام نظم المعلومات الجغرافية
}

\author{
صباح حسين علي \\ مركز التحسس النائي، جامعة الموصل، العرق لعيق
}

الستلخص. من التقنيات الحديثة في تصحيح التشوهات الهندسية

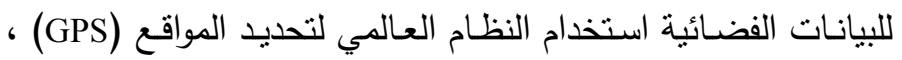
حيث يتت من خـلال ذلك إنشاء علاقة مكانية بين إحداثيات البيان

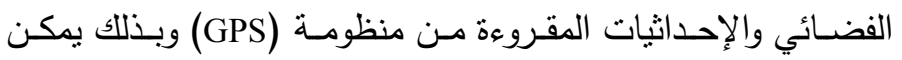
معايرة الأخطاء الموجودة داخل البيان الفضائي والتقليل من تأثيرها. يقدم هذا البحث تطبيقا بحثيا عمليا لبرامجيات نظم المعلومات

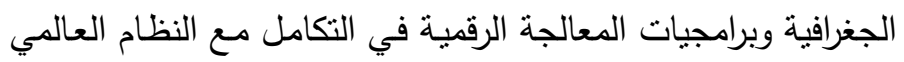

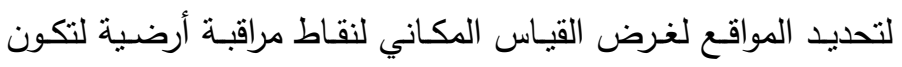

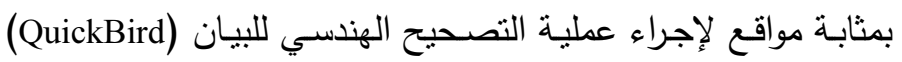
الفضائي لمنطقة الدراسة المعتمدة (مدينة الموصله).

أظهـرت نتـائج الدراسـة الحاليـة، أن ضـعف الدقـة المكانيـة لمنظومة (GPS) المستخدمة في قياس نقاط المراقبة الأرضية كان لها تأثير كبير على عدم كفاءة عملية التصحيح الهندسي والجيوديسي فئيس للبيـان الفضـائي، في حين أن التصـيح عيد الهندسي للبيـان الفضـائي نسبة إلى البيان (QuickBird)

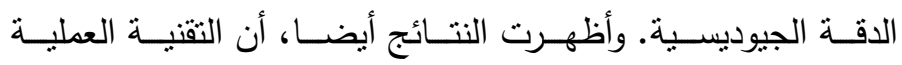

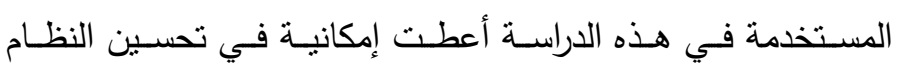


الجيوديسي لإحداثيات البيان الفضـائي المستخدم من أجل تحسين

دقة مسار التتبع الآني لمنظومة (GPS) عند الاعتماد على الخرائط

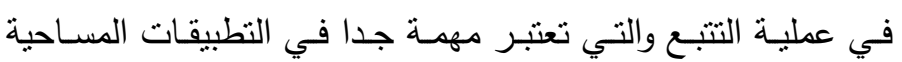

وتخطيط المدن ورسم الخرائط وتطبيقات نظم المعلومـات الجغرافيـة 